\title{
Spatial variation of temperature of surface soil layer adjacent to constructions: A theoretical framework for atmosphere-building-soil energy flow systems
}

\author{
Hongxuan Zhou ${ }^{\text {a, b }}$, Jiang Chang a, b, *, Jing Sun ${ }^{\text {a, b }}$, Chenwei Shang ${ }^{c}$, Fengsen Han ${ }^{\text {d }}$, \\ Dan $\mathrm{Hu}^{\mathrm{d}}$ \\ a School of Architecture and Design, China University of Mining and Technology, Xuzhou, Jiangsu 221116, PR China \\ ${ }^{\mathrm{b}}$ Institute of Architecture and Urban Planning, China University of Mining and Technology, Xuzhou, Jiangsu 221116, PR China \\ ${ }^{\mathrm{c}}$ Center for Human-Environment System Sustainability (CHESS), State Key Laboratory of Earth Surface Processes and Resource Ecology (ESPRE), Beijing \\ Normal University, Beijing 100875, PR China \\ d State Key Laboratory of Urban and Regional Ecology, Research Center for Eco-Environmental Sciences, Chinese Academy of Sciences, Beijing 100085, PR \\ China
}

\section{A R T I C L E I N F O}

\section{Article history:}

Received 3 April 2017

Received in revised form

1 August 2017

Accepted 1 August 2017

Available online 5 August 2017

\section{Keywords:}

Urban construction

Soil temperature

Horizontal heat impact

Energy factor

Underground urban heat island

Space between buildings

\begin{abstract}
A B S T R A C T
Lack of concern for spatial variation of urban soil temperature does not reflect the importance of soil temperature in ecosystem service. The method of construction-soil micro gradient transects (CSMGT) and in situ observations were applied in this study to understand the mechanism of higher soil temperatures in urban areas and the spatial variation of the temperature of surface soil layer adjacent to constructions. Based on experimental data, a new theoretical framework for atmosphere-building-soil energy flow systems was established to analyse the changing rate of the temperature of surface soil layer $\left(R_{S}\right)$ adjacent to constructions. The results of redundancy analysis and hierarchical partitioning showed horizontal heat flux between building and soil $\left(\mathrm{HHF}_{0}\right)$ played a very important role in driving $\mathrm{R}_{\mathrm{S}}$ along the CSMGT at night, whereas joint effects of multiple energy factors drove it during daytime or on the scale of an entire day. Moreover, a formula was fitted to express the temperature of surface soil layer $\left(\mathrm{T}_{\mathrm{S}}\right)$ along the CSMGT. Each parameter ( $\mathrm{a}, \mathrm{b}$ and $\mathrm{c}$ ) of the equation was significant relative to energy or meteorological factors $(\mathrm{P}<0.01)$, and the distribution of the $\mathrm{P}$ value of parameter $\mathrm{b}$ matched the results of the redundancy analysis and hierarchical partitioning.
\end{abstract}

() 2017 Published by Elsevier Ltd.

\section{Introduction}

Urban soil is an important carrier of urban ecosystems and plays a crucial role in urban areas. Soil thermal environments relate to a citizen's daily life and many ecosystem processes [1,2]. In recent decades, accelerated global urbanization has changed surface properties significantly in urban areas, and a great quantity of buildings and roads made of concrete and asphalt have taken the place of original vegetation [3], forming unique micrometeorological conditions. On the one hand, these structures provide human beings with places to conduct daily activities and convenient transportation options, making a highly effective urban

\footnotetext{
* Corresponding author. School of Architecture and Design, China University of Mining and Technology, Xuzhou, Jiangsu 221116, PR China.

E-mail address: changjiang102@163.com (J. Chang).
}

system. On the other hand, a series of negative effects result from these structures, such as the urban heat island effect [4].

Due to being covered and sealed by impervious materials (asphalt, concrete and stone) [5], the physical, chemical and biological properties of soil are gradually changed by influences of structures and anthropogenic activities. Compacted and hardened soil is distributed widely in urban areas and most of the soil is isolated from the atmosphere, this type of soil limits gas effusion and rainfall infiltration, thus changing natural habitats. Moreover, energy transfer processes are changed by structures and anthropogenic activities [5]. Many scholars have reported an upward trend of soil temperature in urban areas [6-11] because of the synergistic action of multiple factors, such as energy flows within and between various spheres $[5,12]$. Soil temperature links many ecosystem processes and structures directly, such as food webs, soil heterotrophic respiration, microbial decomposition, nutrient 
cycling, root respiration, and $\mathrm{C}$ and $\mathrm{N}$ mineralization [13-16]. Changes in soil thermal processes caused by structures and anthropogenic activities may lead to a degradation of soil ecological services. Thus, it is of great scientific significance to do researches on spatial variation of temperature of surface soil layer adjacent to constructions.

Gradient analysis is a traditional method used in ecological research. It has been applied in vegetation research [17] and in the analysis of urban landscape patterns [18]. In recent years, a wider scope regarding gradient analysis has been used, which has produced abundant results $[19,20]$. Therefore, gradient analysis can be appropriately applied to researches at an urban scale.

Numerous studies have focused on the relationship between air temperature and soil temperature [21,22], the process of how buildings lose heat to soil [13,23-25] and the response of the thermal performance of facades to external circumstances [26,27]. There have been few studies of the energy connections between the atmosphere, buildings and soil, and few studies that have considered exploring the spatial variation of soil temperature adjacent to buildings. Using gradient analysis, the aim of this research was to establish a preliminary theoretical framework for the atmospherebuilding-soil energy flow system to study the horizontal spatial distribution of the temperature of surface soil layer $\left(T_{S}\right)$ next to building facades in summer and to determine influencing factors. Additionally, an equation was fitted to express the relationship between the distance from a building and the $\mathrm{T}_{\mathrm{S}}$ and influencing ecological and meteorological factors for the parameters of the equation were found out.

\section{Method}

\subsection{Site condition}

The research site is located in the Haidian District, Beijing City, China $\left(40.008^{\circ} \mathrm{N}, 116.337^{\circ} \mathrm{E}\right)$. Summer is hot and humid in the region, with a sunshine duration of approximately $230 \mathrm{~h}$ per month. Several buildings, roads, and green spaces are distributed throughout the study area, which has loam soil (density of soil in study area is shown in Section S1 in the Supplemental Materials). The detailed situation for selected sample areas can be described as follows: most of the surface is evenly covered by grass (approximately $0.1 \mathrm{~m}$ in height), there are no large trees but some arbuscles were planted in the selected sample area, and sunshine is not blocked by any vegetation in this area.

\subsection{Theoretical framework}

This study was focuses on the energy connections between the atmosphere, buildings and soil, referred to as the atmospherebuilding-soil energy flow system. Fig. 1 shows energy flows in the atmosphere-building-soil system. In this research, not all energy flows were considered, only those marked as red arrows in Fig. 1, including solar radiation (SR), net radiation (NR), ground radiation (GR), atmospheric counter radiation (ACR), vertical soil heat flux (VHF), horizontal heat flux between building and soil $\left(\mathrm{HHF}_{0}: 0 \mathrm{~m}\right.$ from baseline) and horizontal heat flux in soil $\left(\mathrm{HHF}_{20}: 0.2 \mathrm{~m}\right.$ from baseline, $\mathrm{HHF}_{30}$ : $0.3 \mathrm{~m}$ from baseline, and $\mathrm{HHF}_{60}: 0.6 \mathrm{~m}$ from baseline).

Sensible heat flux $(\mathrm{H})$ and latent heat flux (LE) are very important energetic factors that influence soil temperature very much, but they had to be ignored in this study, due to lack of relevant equipment to investigate them. The assessment of excluding sensible and latent heat flux from the theoretical framework was shown in the Section S2 in the Supplemental Materials. The result indicated that it did not influence the final conclusion without $\mathrm{H}$ and LE.

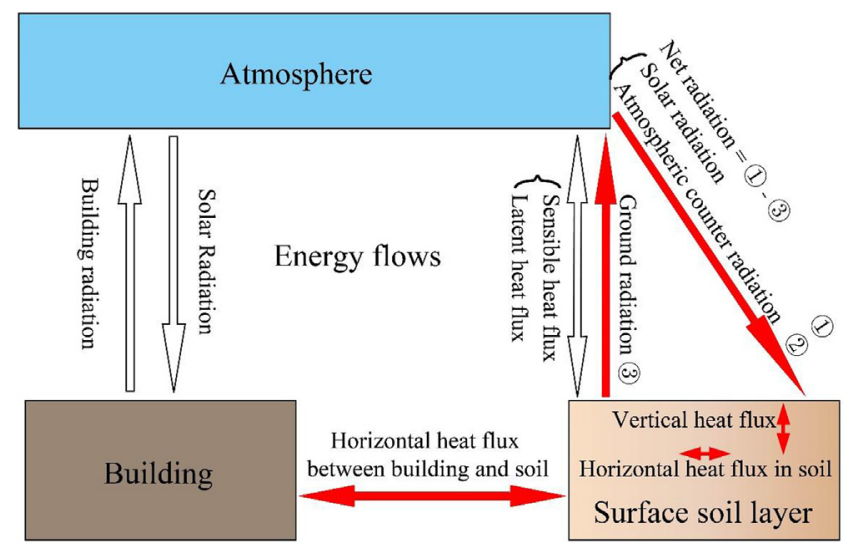

Fig. 1. Preliminary theoretical framework of atmosphere-building-soil energy flow systems.

\subsection{Layout of the CSMGT}

The scale of study changes with different research objects; hence, every study has to be conducted on an appropriate scale or it may lead to incorrect conclusions. Due to soil physical properties, soil temperature changes significantly at depths of $0.3-0.4 \mathrm{~m}$ on a diurnal scale $[7,28]$. Therefore, this research was conducted on a micro scale, with the gradient analysis scaled down the centimetre level. The construction-soil micro gradient transect (referred to as the CSMGT $[29,30]$ henceforth) was considered appropriate for this research.

The green space next to one south facade was selected as the sample area for the experimental CSMGT. Observation points for soil temperature sensors were set as $0,0.05,0.1,0.15,0.2,0.3,0.4$, $0.6,0.9$ and $1.5 \mathrm{~m}$ from the construction baseline respectively, where soil temperature were arranged (Fig. 2c). All observation points were in a straight line.

\subsection{In situ observations}

In situ observations are widely applied in ecological studies and often with reliable results [31-34]. We made in situ observations of $\mathrm{T}_{\mathrm{S}}$ in this research. The entire observation period was divided into two phases. Phase I involved the analysis of changing rate of temperature of surface soil layer $\left(\mathrm{R}_{\mathrm{S}}\right)$ along the CSMGT and its influencing energy factors; a statistical approach was applied to explain the energy mechanisms of $R_{S}$. Phase II involved fitting the data to an appropriate formula and determining which energy factors affect the parameters of the equation directly. The observation period and meteorological conditions are listed in Table 1.

Both phases included sunny days (with a total cloud cover less than $20 \%$ ), partly sunny days (with a total cloud cover between $20 \%$ and $80 \%$ ), cloudy days (with a total cloud cover greater than $80 \%$ ) and rainy days.

$\mathrm{T}_{\mathrm{S}}$ were observed with soil temperature sensors (unit: $\mathrm{K}$, sensor accuracy: $0.2 \mathrm{~K}$ ) and stored with data loggers. The arrangement of soil temperature sensor was shown in Section S3 in the Supplemental Materials. The sampling interval was $1 \mathrm{~min}$, the logging interval was $10 \mathrm{~min}$ and data for each sensor were averaged for each hour (0-59th $\mathrm{min})$. $\mathrm{T}_{\mathrm{S}}$ at different observation points were recorded as $T_{0}, T_{5}, T_{10}, T_{15}, T_{20}, T_{30}, T_{40}, T_{60}, T_{90}$ and $T_{150}$. Soil temperature differences between two adjacent observation points $(\Delta \mathrm{T})$ were recorded as $\Delta \mathrm{T}_{0}, \Delta \mathrm{T}_{5}, \Delta \mathrm{T}_{10}, \Delta \mathrm{T}_{15}, \Delta \mathrm{T}_{20}, \Delta \mathrm{T}_{30}, \Delta \mathrm{T}_{40}, \Delta \mathrm{T}_{60}$ and $\Delta \mathrm{T}_{90}$.

Most meteorological data were gathered and logged with a 

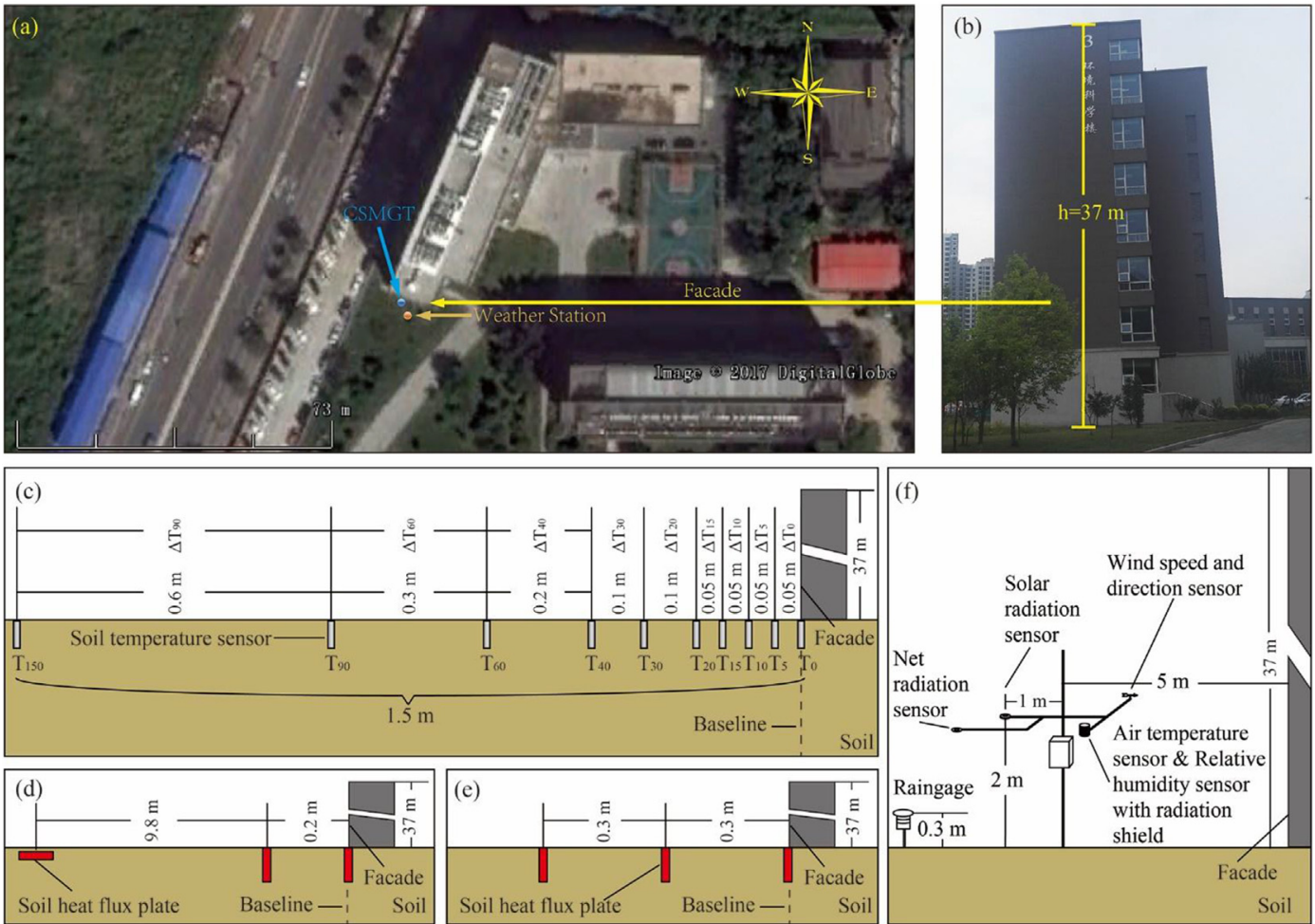

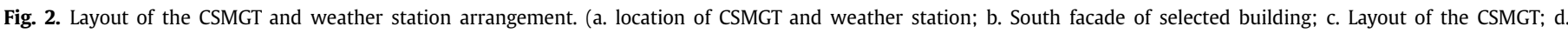
Arrangement of soil heat flux plate during the Phase I; e. Arrangement of soil heat flux plate during the Phase II; f. Weather station and its sensors.)

Table 1

Weather condition during the two observations.

\begin{tabular}{|c|c|c|c|c|c|c|c|c|c|c|c|c|c|c|c|}
\hline \multicolumn{2}{|l|}{ Phase I } & \multicolumn{6}{|c|}{ June } & \multicolumn{8}{|l|}{ July } \\
\hline \multicolumn{2}{|l|}{ Date } & \multicolumn{2}{|l|}{27} & 28 & 29 & \multicolumn{2}{|c|}{30} & 1 & \multicolumn{2}{|l|}{2} & 3 & 4 & \multicolumn{2}{|l|}{ 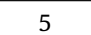 } & 6 \\
\hline \multicolumn{2}{|l|}{ TCC (\%) } & & 33 & 99 & \multicolumn{2}{|c|}{43} & 61 & \multicolumn{2}{|l|}{80} & 73 & 69 & & 48 & 58 \\
\hline \multicolumn{2}{|c|}{$\mathrm{SR}_{\mathrm{m}}\left(\mathrm{W} / \mathrm{m}^{2}\right)$} & \multicolumn{2}{|c|}{475} & 461 & 333 & \multicolumn{2}{|c|}{321} & 186 & \multicolumn{2}{|c|}{75.7} & 123 & 270 & & 272 & 161 \\
\hline \multicolumn{2}{|c|}{ Ta-max (K) } & \multicolumn{2}{|c|}{307} & 309 & 308 & \multicolumn{2}{|c|}{308} & 304 & \multicolumn{2}{|c|}{299} & 303 & 306 & & 305 & 305 \\
\hline \multicolumn{2}{|c|}{ Ta-min (K) } & \multicolumn{2}{|c|}{294} & 297 & 298 & \multicolumn{2}{|c|}{298} & 294 & \multicolumn{2}{|c|}{294} & 297 & 297 & & 298 & 298 \\
\hline \multicolumn{2}{|l|}{$\mathrm{P}(\mathrm{mm})$} & \multicolumn{2}{|l|}{0} & 0 & 0 & \multicolumn{2}{|l|}{0} & 0 & \multicolumn{2}{|c|}{48.1} & 0 & 0 & 0 & 0 & 0 \\
\hline \multicolumn{16}{|c|}{ Phase II August } \\
\hline Date & 1 & 2 & 3 & 4 & 5 & 6 & 7 & 8 & 9 & 10 & 11 & 12 & 13 & 14 & 15 \\
\hline TCC (\%) & 25 & 21 & 50 & 81 & 99 & 44 & 28 & 16 & 20 & 8 & 54 & 76 & 48 & 3 & 7 \\
\hline $\begin{array}{l}\mathrm{SR}_{\mathrm{m}} \\
\quad(\mathrm{W} / \\
\left.\mathrm{m}^{2}\right)\end{array}$ & 184 & 234 & 178 & 845 & 300 & 424 & 406 & 315 & 311 & 455 & 426 & 342 & 72 & 440 & 414 \\
\hline $\begin{array}{c}\text { Ta-max } \\
(\mathrm{K})\end{array}$ & 307 & 309 & 309 & 9301 & 307 & 309 & 307 & 7306 & 306 & 308 & 308 & 307 & 298 & 8305 & 307 \\
\hline $\begin{array}{c}\text { Ta-min } \\
(\mathrm{K})\end{array}$ & 299 & 300 & 299 & 9293 & 294 & 295 & 296 & 296 & 292 & 294 & 295 & 294 & 291 & 1292 & 294 \\
\hline $\mathrm{P}(\mathrm{mm})$ & 0 & 0 & 0.5 & 16.2 & 0 & 0 & 0 & 0 & 0 & 8 & 0 & 0 & 20 & 0 & 0 \\
\hline
\end{tabular}

Note: TCC is total cloud cover, $\mathrm{SR}_{\mathrm{m}}$ is mean solar radiation, Ta-max is the maximum air temperature, Ta-min is the minimum air temperature and $\mathrm{P}$ is precipitation.

weather station that was placed by the authors, $5 \mathrm{~m}$ from the facade. Weather station sensors measured air temperature (unit: $\mathrm{K}$, sensor accuracy: $0.25 \mathrm{~K}, 2 \mathrm{~m}$ above the ground surface), relative humidity (sensor accuracy: $2 \%, 2 \mathrm{~m}$ above the ground surface), SR (unit: $\mathrm{W} / \mathrm{m}^{2}$, sensor accuracy: $3 \%, 2 \mathrm{~m}$ above the ground surface), NR (unit: $\mathrm{W} / \mathrm{m}^{2}$, sensor sensitivity: $10 \mu \mathrm{V} / \mathrm{W} / \mathrm{m}^{2}, 2 \mathrm{~m}$ above the ground surface), VHF (unit: $\mathrm{W} / \mathrm{m}^{2}$, sensor accuracy: $5 \%, 0.02 \mathrm{~m}$ beneath the ground surface, only during the Phase I), $\mathrm{HHF}_{0}$ and $\mathrm{HHF}_{20}$ (unit: $\mathrm{W} / \mathrm{m}^{2}$, sensor accuracy: $5 \%, 0.01 \mathrm{~m}$ beneath ground, 0 and $0.2 \mathrm{~m}$ from construction baseline respectively, upside faces to construction and downside faces to soil, only during Phase I, Fig. 2) and $\mathrm{HHF}_{0}, \mathrm{HHF}_{30}$ and $\mathrm{HHF}_{60}$ (unit: $\mathrm{W} / \mathrm{m}^{2}$, sensor accuracy: $5 \%$, $0.01 \mathrm{~m}$ beneath ground, $0,0.3$ and $0.6 \mathrm{~m}$ from construction baseline respectively, upside faces to construction and downside faces to soil, only during Phase II). The sampling interval was $1 \mathrm{~min}$ and the logging interval was 10 min.

Total cloud cover was obtained from the European Centre for Medium-Range Weather Forecasts, with an observation step of $6 \mathrm{~h}$ and logging timestamps of 2:00, 8:00, 14:00 and 20:00 Beijing time. The coordinates of the total cloud cover data were $40.000^{\circ} \mathrm{N}$, $116.375^{\circ} \mathrm{E}$, which was $3.39 \mathrm{~km}$ from the study site.

\subsection{Calculation of ACR and GR}

ACR was calculated by applying Weng's method [35], shown as formula (1):

$\mathrm{ACR}=\sigma \mathrm{T}^{4} \times[0.536+0.128 \ln (1+\mathrm{E})]\left(1+0.145 \mathrm{n}^{2}\right)$

where $\sigma$ is the Stefan-Boltzmann constant, T is air temperature $(K)$, $\mathrm{n}$ is total cloud cover, and $\mathrm{E}$ is vapour pressure, calculated with formula (2):

$\mathrm{E}=\mathrm{E}_{\mathrm{W}} \times \mathrm{RH}$

where $E_{W}$ is saturation vapour pressure and $R H$ is relative humidity. $E_{W}$ changes with air temperature and could have been calculated with formula (3) [36]:

$E_{W}=e^{\left[16.37379-\frac{38763.659}{T_{a}+229.73}\right]}$

where $T_{a}$ is air temperature $\left({ }^{\circ} \mathrm{C}\right)$.

However, due to a lack of continuous hourly observation data for 
total cloud cover, formula (1) was simplified as formula (4) [35]:

$\mathrm{ACR}=\sigma \mathrm{T}^{4} \times[0.536+0.128 \ln (1+\mathrm{E})]$

ACR was calculated based on formulas (2), (3) and (4).

GR was calculated as the SR minus the NR and then minus the ACR. NR was measured with a net radiometer. The output value of it is only the net radiation, not including the longwave or shortwave (downward and upward). While SR measured with a pyranometer, which investigated downward radiation only. Therefore, GR was calculated through "SR - NR - ACR", meaning that only upward radiation was left and it included both the reflected solar radiation and thermal radiation from the ground.

\subsection{Data processing}

Curve fitting tools in Sigma Plot 10.0 were used to fit curves based on the available experimental data and to obtain the model parameters. The simulation results showed the $P$ values for each parameter.

The non-parametric Spearman test in SPSS 17.0 was used to conduct correlation analysis between available $\mathrm{T}_{\mathrm{S}}$ data and meteorological factors data as well as between the parameters and the meteorological factors data.

Redundancy analysis aims to find one or a group of variables among many factors to explain significant environmental variation, meaning that the more one or a group of variables can explain the environmental variation, the higher the effect of contribution. In recent years, redundancy analysis was developed with the vegan package in $\mathrm{R}$ platform [37]. Many scholars have produced many important conclusions by using redundancy analysis in different fields [38-41].

The analytic hierarchy process is also a statistical analysis package (hier.part) that runs on the R platform. It has been applied successfully by many scholars in their research [42-44]. The analytic hierarchy process was used to analyse $R_{S}$ and energy factors in this research. By using this method, the contributions of different meteorological factors on $\mathrm{R}_{\mathrm{S}}$ were calculated.

The two-tailed T test in SPSS 17.0 was applied to verify that there were significant differences between the variable coefficients of $\mathrm{T}_{0}$ and $\mathrm{T}_{20}$ as well as between $\mathrm{T}_{0}, \mathrm{~T}_{30}$ and $\mathrm{T}_{60}$, with a confidence band of $95 \%$.

\section{Results}

\subsection{Spatial variance of $T_{S}$ along the CSMGT}

By applying the mean $T_{S}$ in the observation period, the spatial distribution of $\mathrm{T}_{\mathrm{S}}$ is clearly observed; along the CSMGT, the slope of the curve is sharp at first and then turns flat (Fig. 3). Additionally, $\Delta \mathrm{T}$ goes down with distance from the baseline (Fig. 3).

During the observation period, for the mean $\mathrm{T}_{\mathrm{S}}$, the highest value exhibited at the $0 \mathrm{~m}$ point $(301.35 \mathrm{~K})$ and the lowest value at the $1.5 \mathrm{~m}$ point $(299.57 \mathrm{~K})$; the gap between them was $1.77 \mathrm{~K}$.

\subsection{Correlation between $R_{S}$ and energy factors}

In this study, $\mathrm{R}_{S}$ is defined as a variable of spatial heterogeneity of $T_{S}$ along the CSMGT, indicating the spatial variation in $T_{S}$ with distance away from the baseline. $\mathrm{R}_{S}$ is expressed as follows:

$\mathrm{R}_{\mathrm{S}}=\Delta \mathrm{T}_{0-20} / \mathrm{D}$

where $\Delta \mathrm{T}_{0-20}$ is the difference between $\mathrm{T}_{0}$ and $\mathrm{T}_{20}$, and $\mathrm{D}$ is the distance between $T_{0}$ and $T_{20}$; here $D$ is $0.2 \mathrm{~m}$. Usually in this

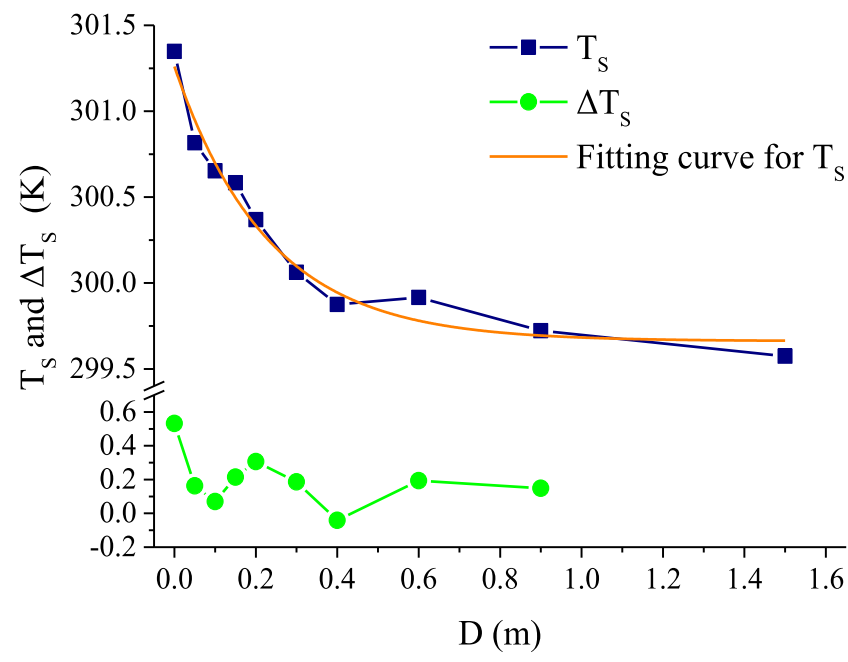

Fig. 3. Spatial variance of $T_{S}$ and $\Delta T$.

research, the value of $R_{S}(K / m)$ is expressed by an hour-scale calculation by formula (5).

Spearman correlation analysis was conducted between $\mathrm{R}_{S}$ and various energy factors, including SR, NR, GR, ACR, $\mathrm{HHF}_{0}, \mathrm{HHF}_{20}$ and VHF in Phase I.

Table 2 shows the correlation coefficients between $R_{S}$ and the energy factors in Phase I; all factors chosen were extremely significantly correlated to $R_{S}(P<0.01)$, positively for $S R, N R, G R$, ACR, $\mathrm{HHF}_{0}$ and VHF and negatively for $\mathrm{HHF}_{20}$.

\subsection{Redundancy analysis}

Based on different energy processes, energy factors were grouped into three categories: (1) Processes in the Atmosphere, including NR, GR and ACR; (2) Processes in Buildings, including $\mathrm{HHF}_{0}$ only; and (3) Processes in Soil, including VHF and $\mathrm{HHF}_{20}$ only in Phase I. SR data were used to differentiate daytime (SR $>0)$ with the night $(S R=0)$.

Phase I data were analysed by applying redundancy analysis; the result is exhibited in Fig. 4:

(1) For an entire day (Fig. 4a), the amount of variation captured by processes in the Atmosphere, Building and Soil was $80.56 \%$ for $\mathrm{R}_{\mathrm{S}}$, indicating that the theoretical framework for atmosphere-building-soil energy flow systems could explain $80.56 \%$ the mechanism of $R_{S}$, the main reason for higher soil temperature next to facade was due to the theoretical framework. The undetermined variation could be attributed for factors not included in the theoretical framework. The decomposition of the variation showed that the largest fraction of the variability in $R_{S}$ was accounted for by the joint

Table 2

Correlation coefficient between $\mathrm{R}_{\mathrm{S}}$ and energetic factors.

\begin{tabular}{ll}
\hline Energy factors & Correlation coefficient \\
\hline SR & $0.651^{* *}$ \\
$\mathrm{NR}$ & $0.549^{* *}$ \\
$\mathrm{ACR}$ & $0.196^{* *}$ \\
$\mathrm{GR}$ & $0.725^{* *}$ \\
$\mathrm{HHF}_{0}$ & $0.869^{* *}$ \\
$\mathrm{HHF}_{20}$ & $-0.388^{* *}$ \\
$\mathrm{VHF}^{*}$ & $0.711^{* *}$ \\
\hline Note ${ }^{* *}$ means correlation is significant at the 0.01 level
\end{tabular}




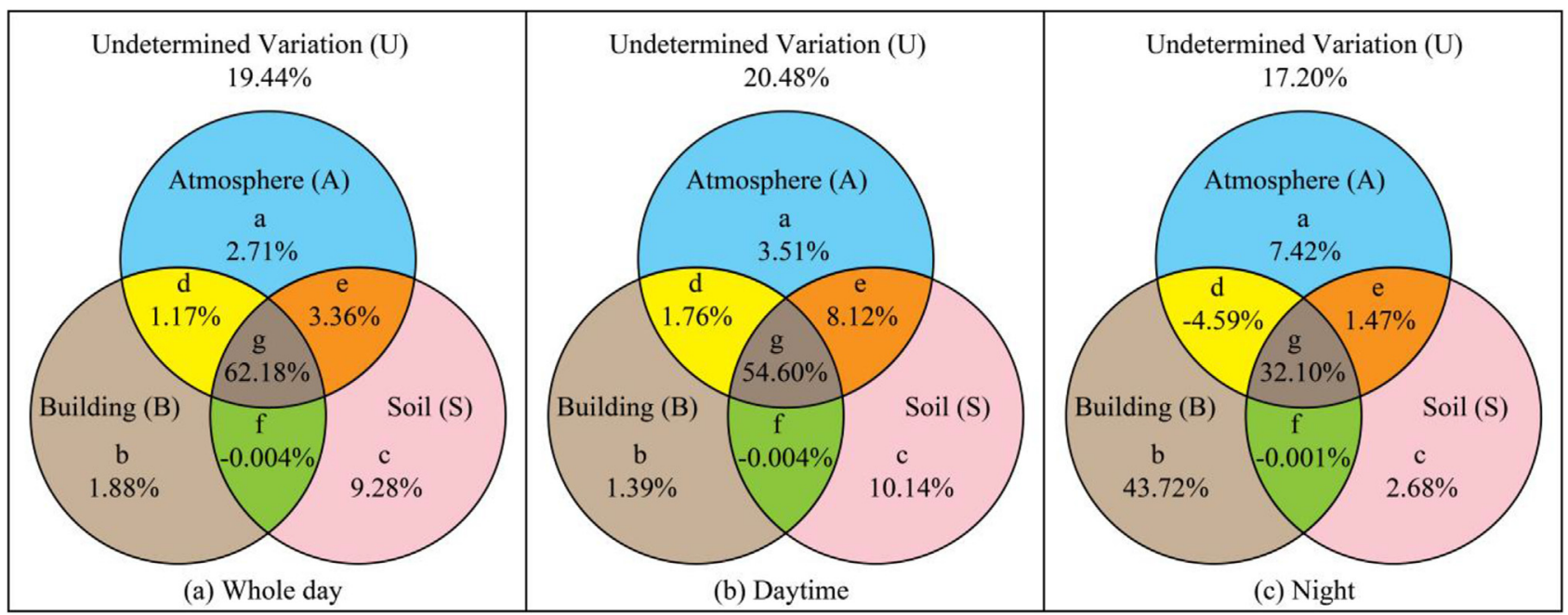

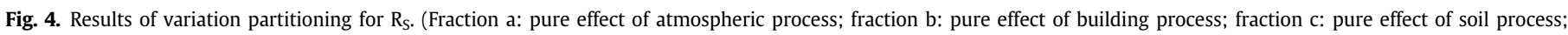

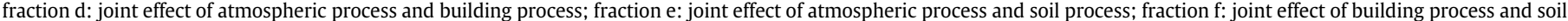
process; and fraction g: joint effect of the three processes.).

effect of all three process groups (fraction g; 62.18\%). The pure effect of each energy process was relatively low (fraction a, b and c; $2.71 \%, 1.88 \%$ and $9.28 \%$, respectively), $13.86 \%$ in total. The joint effects of each pair of energy processes contributed $4.52 \%$ of $\mathrm{R}_{\mathrm{S}}$ in all (fraction d, e and f; $1.17 \%, 3.36 \%$ and $-0.004 \%$, respectively). These meant that all of energy processes did not act alone but in concert.

(2) For daytime (Fig. 4b), the amount of variation captured by processes in the Atmosphere, Building and Soil was 79.52\% for $\mathrm{R}_{\mathrm{S}}$, meaning that the $79.52 \%$ of variability could be explained with the theoretical framework and the rest $20.48 \%$ was not explained by the theoretical framework because of some energetic and environmental factors were not considered. The decomposition of the variation showed that the largest fraction of the variability in $R_{S}$ was accounted for by the joint effect of all the three process groups (fraction g; $54.60 \%$ ). The pure effect of each energy process was relatively low (fraction a, b and c; $3.51 \%, 1.39 \%$ and $10.14 \%$, respectively), $15.05 \%$ in total. The joint effects of each pair of energy processes contributed $9.87 \%$ of $\mathrm{R}_{\mathrm{S}}$ in all (fraction $\mathrm{d}$, e and f; $1.76 \%, 8.12 \%$ and $-0.004 \%$, respectively). Similar with above consistent result, the three energetic processes work together.

(3) For night (Fig. 4c), the amount of variation captured by processes in the Atmosphere, Building and Soil was 82.80\% for $R_{S}$. It also suggested that the theoretical framework for atmosphere-building-soil energy flow systems accounted for $82.80 \%$ of the explanation. The decomposition of the variation showed that the largest fraction of the variability in $\mathrm{R}_{\mathrm{S}}$ was accounted by the Building process (fraction $b ; 43.72 \%$ ), then by the joint effect of all the three process groups (fraction g; 32.10\%). The pure effect of the other two energy processes was relatively low (fraction a and c; $7.42 \%$ and $2.68 \%$, respectively), $10.10 \%$ in total. The joint effects of each of two energy processes contributed $-3.12 \%$ of $\mathrm{R}_{\mathrm{S}}$ in all (fraction d, e and f; $-4.56 \%, 1.47 \%$ and $-0.001 \%$, respectively).
It indicated that soil process played a leading role on $\mathrm{R}_{\mathrm{S}}$ next to the south facade at night.

\subsection{Hierarchical partitioning}

By using the SR data, the observation was divided into daytime $(S R>0)$ and the night $(S R=0)$ to help our understanding of the roles the energy factors played at different times. The results of hierarchical partitioning were largely in accordance with those of redundancy analysis (Fig. 5).

(1) For an entire day (Fig. 5a and b), the independent explanatory power of each energy factor was $18.51 \%, 2.52 \%, 15.69 \%$, $13.76 \%, 18.54 \%$ and $5.37 \%$ for NR, ACR, GR, $\mathrm{HHF}_{0}, \mathrm{VHF}$ and $\mathrm{HHF}_{20}$, respectively. Most of the explained variation was related to the joint effects of the variables (NR, GR, $\mathrm{HHF}_{0}$ and VHF; $43.90 \%, 39.60 \%, 36.44 \%$ and $44.58 \%$, respectively), except for ACR and $\mathrm{HHF}_{20}(-0.50 \%$ and $0.47 \%)$. The decreasing order of the individual contributions of each energy factor was VHF (24.92\%), NR (24.87\%), GR (21.09\%), $\mathrm{HHF}_{0}$ (18.50\%), $\mathrm{HHF}_{20}(7.22 \%)$ and ACR (3.38\%). The result meant these energy factors preferred working in concert, rather than taking effects alone. Therefore, no energy factors played a leading role in an entire day.

(2) For daytime (Fig. 5c and d), the independent explanatory power of each energy factor was $20.98 \%, 1.77 \%, 15.75 \%$, $12.17 \%, 18.93 \%$ and $4.86 \%$ for NR, ACR, GR, HHF, VHF and $\mathrm{HHF}_{20}$, respectively. Most of the explained variation was related to the joint effects of the variables (NR, GR, $\mathrm{HHF}_{0}$ and VHF; $42.77 \%, 37.55 \%, 31.29 \%$ and $43.36 \%$, respectively), except for ACR and $\mathrm{HHF}_{20}(-1.68 \%$ and $-2.08 \%)$. The individual contributions of each energy factor were, in decreasing order, $\mathrm{NR}(28.18 \%), \operatorname{VHF}(25.42 \%), \mathrm{GR}(21.15 \%), \mathrm{HHF}_{0}$ (16.35\%), $\mathrm{HHF}_{20}$ (6.53\%) and ACR (2.37\%). Similar with above, at daytime no energy factors dominated the $\mathrm{R}_{\mathrm{S}}$ and it was an effect of multiple-factor. 

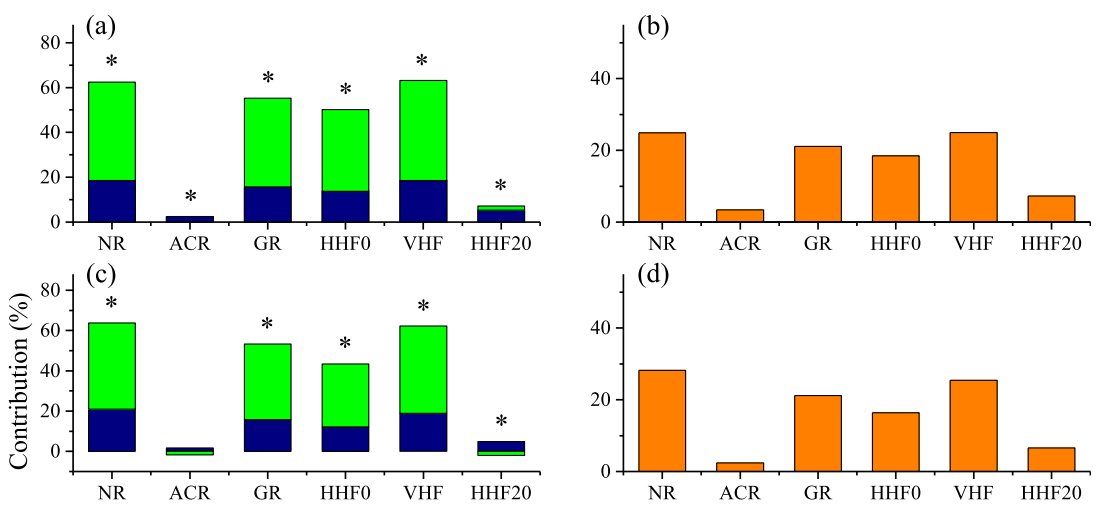

(d)
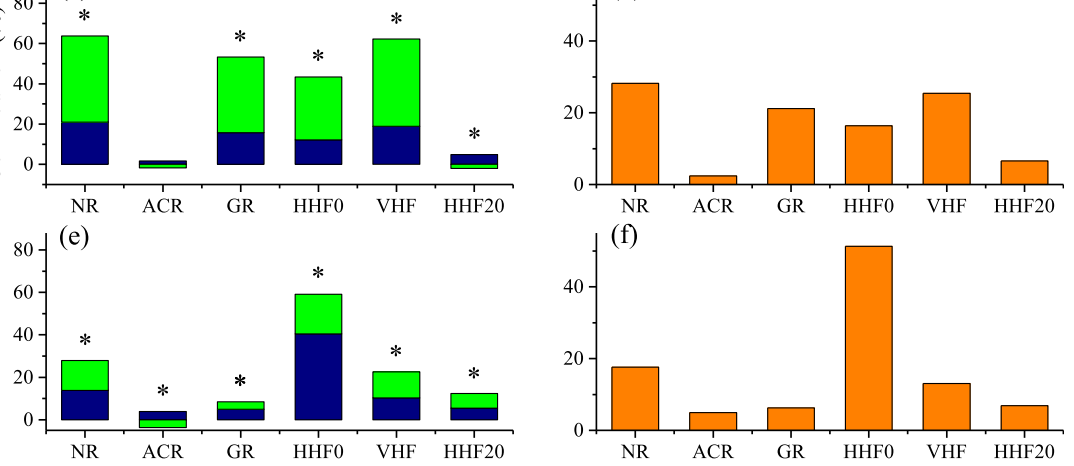

Factors

Independent contribution

Joint contribution

Individual contribution

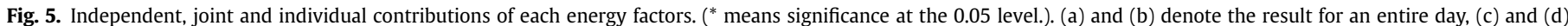

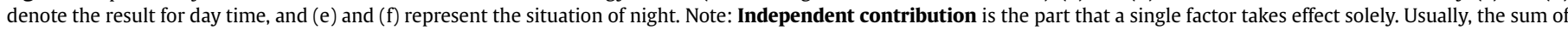

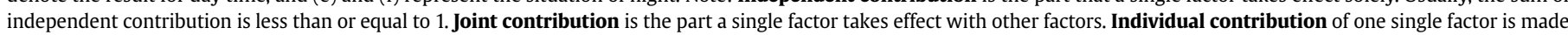
up of 2 parts. One is independent contribution of one single factor and the other is the part of joint contribution that the single factor makes.

(3) For night (Fig. 5e and f), the independent explanatory powers of $\mathrm{NR}, \mathrm{ACR}, \mathrm{GR}, \mathrm{HHF}_{0}$, VHF and $\mathrm{HHF}_{20}$ were $13.87 \%, 3.89 \%$, $4.90 \%, 40.40 \%, 10.27 \%$ and $5.39 \%$, respectively. Among all energy factors, $\mathrm{HHF}_{0}$ had the largest independent effect. Moreover, part of the explained variation was related to the joint effects of the variables (NR, GR, $\mathrm{HHF}_{0}, \mathrm{VHF}$ and $\mathrm{HHF}_{20}$; $14.02 \%, 3.53 \%, 18.78 \%, 12.25 \%$ and $6.99 \%$, respectively), except for ACR (-3.67\%). The individual contribution of each energy factor was, in decreasing order, $\mathrm{HHF}_{0}$ (51.32\%), NR (17.62\%), $\mathrm{HHF}_{20}$ (13.04\%), ACR (6.85\%), GR (6.22\%) and VHF (4.94\%). Different with above results, the situation changed at night; $\mathrm{HHF}_{0}$ played a dominant role on controlling the $\mathrm{R}_{\mathrm{S}}$, due to its high independent and individual contribution.

Similar result was acquired next to a road in the study area (Section S4).

\subsection{Curve fitting}

Based on the spatial variation of $T_{S}$ next to the south facade, $a$ formula for $\mathrm{T}_{\mathrm{S}}$ was generated as follows:

$\mathrm{T}_{\mathrm{S}}=\mathrm{a} \times \exp ^{(-\mathrm{bx})}+\mathrm{c}$

where $\mathrm{x}$ is the distance from the construction baseline $(\mathrm{m})$ and $\mathrm{a}, \mathrm{b}$ and $c$ are parameters of the equation. The formula represents the $T_{S}$ that is $\mathrm{x}$ metres from construction baseline. The formula was generated once for each hour of observation period in Phase II; 360 formulas were fitted using the experimental data in total.

$\mathrm{R}^{2}$ for this fitting was distributed as shown in Table 3:
In total, $77.22 \%$ of $\mathrm{R}^{2}$ values were greater than 0.80 and usually appeared after nightfall and before midnight; whereas $13.06 \%$ of $\mathrm{R}^{2}$ values were less than 0.50 and often appeared during dawn and before noon, or during or after rain.

The significance of each parameter ( $P$ value) was determined for three categories: (1) less than $0.01,(2)$ greater or equal to 0.01 and less than 0.05 and (3) greater or equal to 0.05 . The frequency of the $P$ value for each parameter is shown in Table 4.

Among the three parameters, parameter c shows the best fit, followed by a and b, respectively. P values for $95.84 \%$ of $P_{c}$ were less than 0.05 , and $P$ values for $91.67 \%$ and $71.11 \%$ of $\mathrm{P}_{\mathrm{a}}$ and $\mathrm{P}_{\mathrm{b}}$, respectively, were less than 0.05 .

\subsection{Relationship between three parameters and meteorological factors}

Based on the $\mathrm{R}^{2}$ value being lower during the rain or after the rain for a period of several hours, which was mentioned in section 3.5 , all the data involved with rain were removed. Moreover, all data when the $P$ value for parameter $b$ was greater than 0.05 were also excluded. Thus, 221 groups of data remained for statistical analysis.

Table 4

Frequency of $\mathrm{P}$ value for the three parameters.

\begin{tabular}{llll}
\hline & $<0.01$ & $\geq 0.01$ and $<0.05$ & $\geq 0.05$ \\
\hline $\mathrm{P}_{\mathrm{a}}$ & $88.89 \%$ & $2.78 \%$ & $8.33 \%$ \\
$\mathrm{P}_{\mathrm{b}}$ & $58.61 \%$ & $12.50 \%$ & $28.89 \%$ \\
$\mathrm{P}_{\mathrm{c}}$ & $95.56 \%$ & $0.28 \%$ & $4.16 \%$ \\
\hline
\end{tabular}

Table 3

Frequency of $\mathrm{R}^{2}$ for the fitting formula.

\begin{tabular}{|c|c|c|c|c|c|}
\hline $\mathrm{R}^{2} \geq 0.95$ & $0.90 \leq \mathrm{R}^{2}<0.95$ & $0.80 \leq \mathrm{R}^{2}<0.90$ & $0.70 \leq \mathrm{R}^{2}<0.80$ & $0.50 \leq \mathrm{R}^{2}<0.70$ & $\mathrm{R}^{2}<0.50$ \\
\hline $44.17 \%$ & $18.61 \%$ & $14.44 \%$ & $5.83 \%$ & $3.89 \%$ & $13.06 \%$ \\
\hline
\end{tabular}


Table 5

Correlation between the three parameters and meteorological data.

\begin{tabular}{|c|c|c|c|c|c|c|c|}
\hline Correlation Coefficient & SR & NR & GR & $\mathrm{HHF}_{0}$ & $\mathrm{HHF}_{30}$ & $\mathrm{HHF}_{60}$ & $\mathrm{Ta}$ \\
\hline Parameter a & $0.409^{* *}$ & $0.317^{* *}$ & $0.425^{* *}$ & $0.790^{* *}$ & $0.338^{* *}$ & $0.326^{* *}$ & $0.649^{* *}$ \\
\hline Parameter b & $0.555^{* *}$ & $0.496^{* *}$ & $0.457^{* *}$ & $0.897^{* *}$ & $0.561^{* *}$ & $0.509^{* *}$ & $0.780^{* *}$ \\
\hline Parameter c & $0.705^{* *}$ & $0.777^{* *}$ & $0.408^{* *}$ & $0.848^{* *}$ & $0.840^{* *}$ & $0.771^{* *}$ & $0.946^{* *}$ \\
\hline
\end{tabular}

Note: ${ }^{* *}$ means correlation is significant at the 0.01 level.

In applying the Spearman correlation analysis, the three parameters showed significant correlation $(P<0.01)$ with the observed meteorological data (Table 5).

Linear regressions between the three parameters and observed meteorological data were conducted one by one. Parameter a and $\mathrm{HHF}_{0}$, parameter $\mathrm{b}$ and the square root of the absolute value of $\mathrm{HHF}_{0}$ and parameter $\mathrm{c}$ and air temperature had the best $\mathrm{R}^{2}$ values (Fig. 6). Additionally, the P value for each linear formula was less than 0.01 .

As shown in Fig. 6, the three parameters were significantly relevant to meteorological factors $(\mathrm{P}<0.01)$ and were represented as follows:

$a=0.056 \mathrm{HHF}_{0}+1.145$

$b=\left\{\begin{array}{c}0.82 \sqrt{\left|\mathrm{HHF}_{0}\right|}+2.044\left(\mathrm{HHF}_{0} \geq 0\right) \\ -0.82 \sqrt{\left|\mathrm{HHF}_{0}\right|}+2.044\left(\mathrm{HHF}_{0}<0\right)\end{array}\right.$

$c=0.549 \mathrm{~T}_{\mathrm{a}}+134.294$

\section{Discussion}

\subsection{The source of horizontal heat flux}

Usually, soil temperature is considered higher in urban areas because of anthropogenic heat. The seasonal or long-term high temperatures of urban infrastructure, such as sewage systems and heating pipes, leads to higher surrounding soil temperatures [45]. Moreover, subway tunnels increase surrounding soil temperatures by $5-10 \mathrm{~K}$ [46], and pipeline and cable tunnels make stable temperature fields in soil $[47,48]$. In addition, constructed objects such as buildings transfer heat from foundations [49,50]. Besides, anthropogenic heat could be the driving force that increases the temperature of shallow aquifers in urban areas [12,51].

The horizontal heat impacts studied in this research were not caused by anthropogenic heat. We attribute the main reasons for this as follows: there were different thermodynamic properties of building materials and soils, causing temperature differences between constructions and soil, which led to $\mathrm{HHF}_{0}$. A couple of scholars have performed research concerning the higher soil temperatures around structures [52-55]. Their research suggested that structures are heat sources for adjacent soil because of different thermal properties and the land cover between soil and structure materials. According to the China National Standard (GB504962009), the heat capacities of concrete is $920 \mathrm{~J} \cdot(\mathrm{kg} \cdot \mathrm{K})^{-1}$ and thermal conductivity of concrete is $1.74 \mathrm{~W} /(\mathrm{m} \mathrm{K})$. The heat capacity of soil changes with moisture (volumetric water content, VMC); the heat capacity of extremely dry soil is the same as concrete, whereas the heat capacity of soil at $50 \%$ of the VMC is $2093 \mathrm{~J} \cdot(\mathrm{kg} \cdot \mathrm{K})^{-1}$. Albedo, another physical property, is different for different materials, at 0.17 for soil and 0.37 for concrete [56]. Additionally, soil usually is covered by vegetation, while structures are not. The factors above dictate that the direction of $\mathrm{HHF}_{0}$ is transferred from a building to the surrounding soil.

\subsection{The driver for spatial variation of $T_{S}$ along the CSMGT}

In this research, $\mathrm{T}_{\mathrm{S}}$ was influenced by many energy factors, including $\mathrm{NR}, \mathrm{GR}, \mathrm{ACR}, \mathrm{HHF}_{0}, \mathrm{VHF}$ and horizontal heat flux in soil $\left(\mathrm{HHF}_{20}, \mathrm{HHF}_{30}\right.$ and $\left.\mathrm{HHF}_{60}\right)$. According to the results of redundancy analysis for the entire day, the joint effect of all three energy processes dominated $R_{s}$. The pure effect of each energy process and the joint effect of each pair of energy processes were not greatly explanatory, especially the joint effect of processes in Building and Soil. For daytime, the result of the redundancy analysis is similar to the result of the redundancy analysis for the entire day. By contrast, the proportion of joint effects and pure effects changed at night. The energy processes in Building became the No. 1 dominant force driving $R_{S}$, and the joint effect of the three energy processes ranked second; other joint effects and pure effects played relatively minor roles. The results of hierarchical partitioning were similar to the results of redundancy analysis; none of the chosen energy factors played a dominant role influencing $\mathrm{R}_{\mathrm{S}}$ for the entire day and for daytime, while the situation became different for night. $\mathrm{HHF}_{0}$ played a dominant role, with its individual contribution exceeding that from all other energy factors. The results of both redundancy
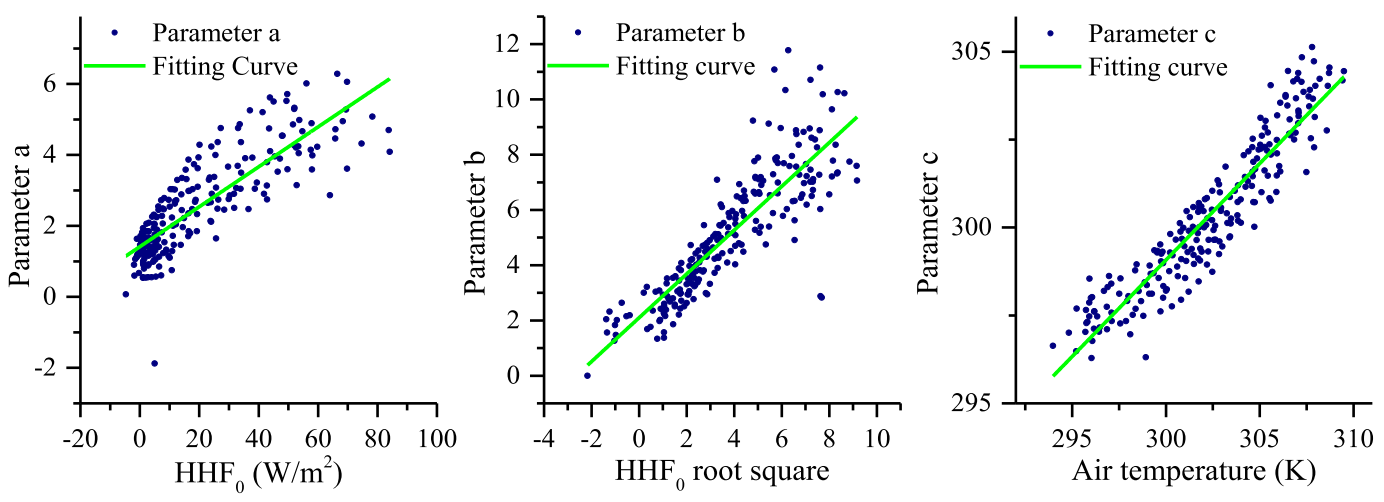

Fig. 6. Linear relation between parameters and meteorological factors. 
analysis and hierarchical partitioning show that $\mathrm{R}_{\mathrm{S}}$ was affected synthetically by energy factors for the entire day and for daytime, but was mainly influenced by $\mathrm{HHF}_{0}$ at night.

Based on the evidence presented, horizontal heat flux is a key energy factor causing variation in $\mathrm{R}_{\mathrm{S}}$. However, $\mathrm{HHF}_{0}$ contributed more effects than $\mathrm{HHF}_{20}$. To further demonstrate this observation, the variable coefficients of $\mathrm{T}_{0}$ and $\mathrm{T}_{20}$ were sampled every $24 \mathrm{~h}$ in Phase I and analysed by T-text to isolate significant differences; the confidence band was $95 \%$. The result of T-tests showed there were significant differences between the variable coefficients of $\mathrm{T}_{0}$ and $\mathrm{T}_{20}(\mathrm{P}<0.05)$. Moreover, the diurnal change of $\mathrm{HHF}_{0}$ and $\mathrm{HHF}_{20}$ exhibited the same evidence (Fig. 7a).

The same method was applied in Phase II to examine the significant differences among the variable coefficients of $T_{0}, T_{30}$ and $\mathrm{T}_{60}$. The results of T-tests showed clearly that the variable coefficient of $\mathrm{T}_{0}$ was significantly different from variable coefficients of $\mathrm{T}_{30}$ and $\mathrm{T}_{60}(\mathrm{P}<0.05)$, whereas there was no significant difference between variable coefficients of $\mathrm{T}_{30}$ and $\mathrm{T}_{60}(\mathrm{P}>0.05)$. Additionally, the diurnal change of $\mathrm{HHF}_{0}, \mathrm{HHF}_{30}$ and $\mathrm{HHF}_{60}$ showed the same evidence (Fig. 7b). All of the evidence shows that $\mathrm{HHF}_{0}$ played a crucial role in driving $\mathrm{R}_{\mathrm{S}}$.

\subsection{Meanings of parameters}

Formula (6) can be used to express $\mathrm{T}_{\mathrm{S}}$ along the CSMGT, with parameters a, b and c representing different meanings, as follows:

(1) If $\mathrm{x}$ is a very large value, formula (6) is close to parameter c, which means that parameter $\mathrm{c}$ is considered to be the $\mathrm{T}_{\mathrm{S}}$ that is not influenced by $\mathrm{HHF}_{0}$. Moreover, soil temperature shows a very good correlation with air temperature in past research [57]. In this study, a similar situation was found between parameter $\mathrm{c}$ and air temperature (Fig. 6c). Due to formula (6) being used to express $T_{S}$, it could be inferred that the parameter $\mathrm{c}$ is the $\mathrm{T}_{\mathrm{S}}$ in urban area, which is beyond the range of influence caused by $\mathrm{HHF}_{0}$.

(2) If $x$ is equal to zero, then formula (6) is equal to " $a+c$ ". Parameter $c$ is affirmed as the $\mathrm{T}_{\mathrm{S}}$ in urban areas, which is beyond the range of influence caused by $\mathrm{HHF}_{0}$ in this study, and parameter $\mathrm{a}$ is considered to be the difference of $\mathrm{T}_{\mathrm{S}}$ between the baseline and the area that is not influenced by $\mathrm{HHF}_{0}$ on a diurnal scale. The soil temperature difference is the reason for soil heat flux; the higher the soil temperature difference, the greater the soil heat flux, and vice versa. In this

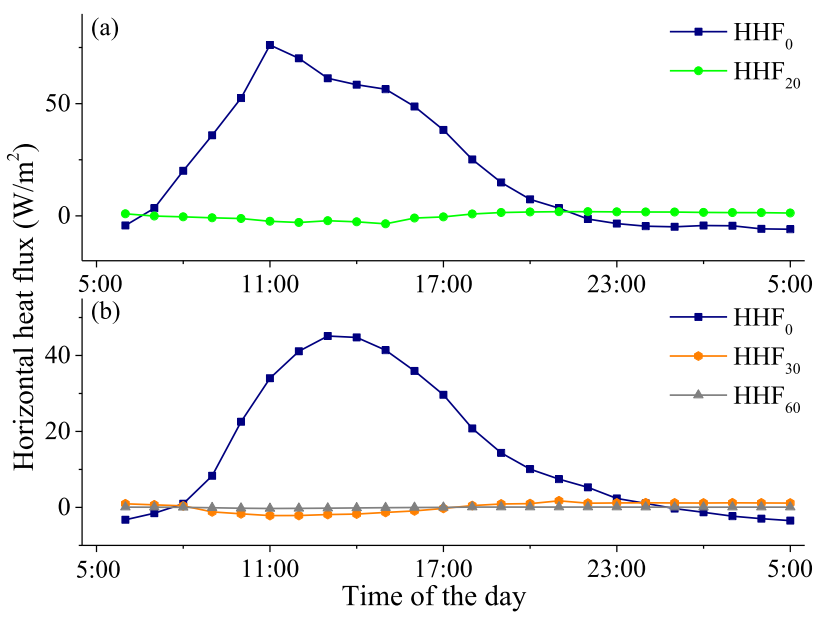

Fig. 7. Comparison between horizontal heat fluxes. study, parameter a shows a positive and linear correlation with $\mathrm{HHF}_{0}$, demonstrating the above inference.

(3) Parameter b, is considered to be a coefficient which is related to the differences of $\mathrm{T}_{\mathrm{S}}$ and the thermal conductivity of soil. Heat flux can be calculated by the following formula:

$\mathrm{q}=-\lambda \frac{\mathrm{d}_{\mathrm{t}}}{\mathrm{d}_{\mathrm{x}}}$

where $d t / d x$ is the change rate of soil temperature and $\lambda$ is the thermal conductivity of soil. Parameter $b$ shows a positive linear correlation with the square root of $\mathrm{HHF}_{0}$ ( $\mathrm{q}$ in formula (10)). Therefore, parameter $\mathrm{b}$ is considered to be a variable that correlates to the change rate of soil temperature and the thermal conductivity of soil.

\subsection{P value of parameter $b$}

According to section 3.5, parameters a and c showed very good statistical fits (95.84\% of $\mathrm{P}_{c}$ and $91.67 \%$ of $\mathrm{P}_{\mathrm{a}}$ are less than 0.05 ), whereas parameter $\mathrm{b}$ showed a relatively high sensitivity to the meteorological environment, especially to drastically changing energy flows, as follows:

(1) As shown in Fig. 8, when $\mathrm{P}_{\mathrm{b}}$ was less than 0.01, high frequency was observed between 16:00 and 0:00 (from sunset to midnight), and low frequency was observed between 7:00 and 11:00 (from sunrise to noon).

(2) When $P_{b}$ was greater than 0.05 , the opposite situation occurred: high frequency was observed between 6:00 and 11:00 (from sunrise to noon), and low frequency was observed between 18:00 and 0:00 (from sunset to midnight) (Fig. 8).

(3) When $P_{b}$ is between 0.01 and 0.05 , the frequency distribution exhibited no regular pattern.

All the evidence showed that formula (6) resulted in a good fit after noon and before dawn. The distribution of frequency of $\mathrm{P}_{\mathrm{b}}$ is largely in accordance with the former results of redundancy analysis and hierarchical partitioning; $\mathrm{HHF}_{0}$ played a dominant role at night rather than during the day.

\section{Conclusion}

By applying the method of CSMGT with in situ observations, a new theoretical framework of atmosphere-building-soil energy flow systems was established to observe and analyse spatial variations of $\mathrm{T}_{\mathrm{S}}$ adjacent to constructions. Combining various statistical approaches, several conclusions were determined, and they support each other. Based on the established theoretical framework

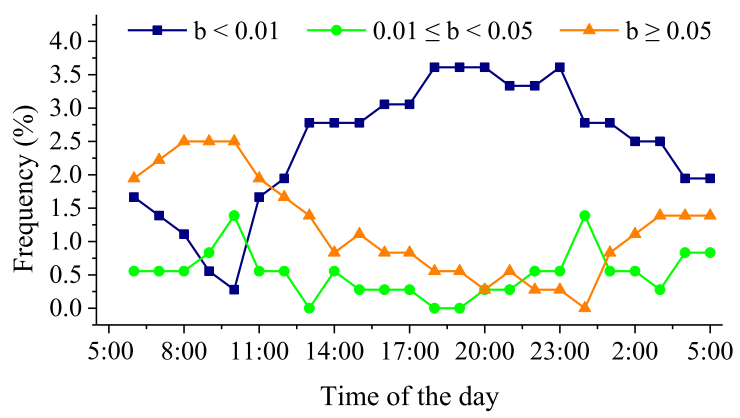

Fig. 8. Distribution of $P_{b}$ on a diurnal scale. 
and statistical results, this study concludes that:

(1) $R_{S}$ is relative to multiple meteorological factors. Energetic processes in the atmosphere, buildings and soil can explain over $80 \%$ of the Rs along the CSMGT, no matter if over an entire day, in the daytime, or at night. The three energy processes play different roles in driving the $\mathrm{R}_{S}$ along the CSMGT for different periods of time. For an entire day and during the daytime, the combination of the three energy processes dominates $\mathrm{R}_{\mathrm{S}}$, explaining $61.64 \%$ and $54.24 \%$ of the variation over the entire day and during daytime, whereas the building processes drive $\mathrm{R}_{\mathrm{S}}$ at night, explaining $43.26 \%$ of the variation.

(2) The six energy factors play different roles in driving the $R_{S}$ through an entire day, in daytime, and at night. For the entire day, various energy factors drive the $R_{S}$ jointly (49.63\%, $18.97 \%, 48.01 \%, 41.62 \%$ and $51.02 \%$ for NR, ACR, GR, HHF 0 and VHF, respectively), and no single factor plays a dominant role (20.29\%, 18.32\%, $14.31 \%$ and $19.12 \%$ for $\mathrm{NR}, \mathrm{GR}, \mathrm{HHF}_{0}$ and $\mathrm{VHF}$, respectively). For daytime, the situation is similar; joint effects were $46.92 \%, 15.34 \%, 44.24 \%, 35.15 \%$ and $48.22 \%$ for $\mathrm{NR}$, ACR, GR, $\mathrm{HHF}_{0}$ and VHF, and independent effects were $20.29 \%, 18.03 \%, 12.46 \%$ and $19.29 \%$ for NR, GR, $\mathrm{HHF}_{0}$ and VHF, respectively. At night, the independent effect of $\mathrm{HHF}_{0}$ (44.69\%) plays a key role in driving the $\mathrm{R}_{\mathrm{S}}$, while other factors play subordinate roles $(12.62 \%, 12.62 \%, 23.86 \%, 16.73 \%$ and 6.52\% for NR, GR, VHF $\mathrm{HHF}_{20}$, and ACR, respectively).

(3) Along the CSMGT next to the south facade, $T_{S}$ changes with the distance from the construction baseline and the relationship between them can be represented by $\mathrm{T}_{\mathrm{S}}=\mathrm{a} \times \exp ^{(-\mathrm{bx})}+\mathrm{c}$. This equation was used to express a kind of relation between $T_{S}$ and energetic factors and it was reliable next to the south facade in summer, if no precipitation happens. Parameters a, b and c were correlated with energy and meteorological factors significantly, positively and linearly $(\mathrm{P}<0.001)$. For the surface soil layer next to the south facade, parameter a can be calculated by $\mathrm{a}=0.056 \mathrm{HHF}_{0}+1.145$; parameter $\mathrm{b}$ can be calculated by $\mathrm{b}=0.82 \sqrt{\left|\mathrm{HHF}_{0}\right|}+2.044\left(\mathrm{HHF}_{0} \geq 0\right)$ or $\mathrm{b}=-0.82 \sqrt{\left|\mathrm{HHF}_{0}\right|}+2.044\left(\mathrm{HHF}_{0}<0\right)$; and parameter $\mathrm{c}$ can be calculated by $\mathrm{c}=0.549 \mathrm{~T}_{\mathrm{a}}+134.294$. Parameter $\mathrm{a}$ is considered to be the differences of $\mathrm{T}_{\mathrm{S}}$ between the construction baseline and areas that are not influenced by $\mathrm{HHF}_{0}$; parameter $b$ is considered to be a coefficient related to the difference of $\mathrm{T}_{\mathrm{S}}$ and the thermal conductivity of soil; and parameter $\mathrm{c}$ is identified as the $\mathrm{T}_{\mathrm{S}}$ that is not influenced by $\mathrm{HHF}_{0}$. All these equations suggested the relation between the parameters and energetic factors.

In this paper, research was reported on the specific mechanisms for spatial variation of the temperature of surface soil layer adjacent to buildings, but further quantitative analyses are needed to for deep soil layers. Additionally, more energy flows need to be considered to improve the theoretical framework of atmospherebuilding-soil energy flow systems.

\section{Acknowledgement}

This research was supported by the Fundamental Research Funds for the Central Universities (2017QNA28). We thank Dr. Tinghao Hu and Mr. Xuehan Wei for their drawing and Mr. Haining Gao for his photo. At last, we thank the three anonymous reviewers for their precious time and pertinent suggestion.

\section{Appendix A. Supplementary data}

Supplementary data related to this article can be found at http:// dx.doi.org/10.1016/j.buildenv.2017.08.002.

\section{References}

[1] M. Bonaiuto, F. Fornara, M. Bonnes, Indexes of perceived residential environment quality and neighbourhood attachment in urban environments: a confirmation study on the city of Rome, Landsc. Urban Plan. 65 (1-2) (2003) $41-52$.

[2] I. van Kamp, K. Leidelmeijer, G. Marsman, A. de Hollander, Urban environmental quality and human well-being: towards a conceptual framework and demarcation of concepts; a literature study, Landsc. Urban Plan. 65 (1-2) (2003) 5-18.

[3] A. Brazel, N. Selover, R. Vose, G. Heisler, The tale of two climates-Baltimore and Phoenix urban LTER sites, Clim. Res. 15 (2) (2000) 123-135.

[4] T.R. Oke, The energetic basis of the urban heat island, Q. J. R. Meteorological Soc. 108 (455) (1982) 1-24.

[5] R. Scalenghe, F.A. Marsan, The anthropogenic sealing of soils in urban areas, Landsc. Urban Plan. 90 (1-2) (2009) 1-10.

[6] H. Halverson, G. Heisler, Soil temperatures under urban trees and asphalt, USDA For. Serv. Res. Pap. NE (USA) 481 (481) (1981) 1-9.

[7] C.-S. Tang, B. Shi, L. Gao, J.L. Daniels, H.-T. Jiang, C. Liu, Urbanization effect on soil temperature in Nanjing, China, Energy Build. 43 (11) (2011) 3090-3098.

[8] N. Turkoglu, Analysis of urban effects on soil temperature in Ankara, Environ. Monit. Assess. 169 (1-4) (2010) 439-450.

[9] F. Kang, S. Tang, Research on soil of green space of urban streets, Jilin For. Sci. Technol. 32 (4) (2003) 43-45.

[10] B. Shi, C. Tang, L. Gao, H. Jiang, C. Liu, Differences in shallow soil temperatures at urban and rural areas, J. Eng. Geol. 20 (1) (2012) 58-65.

[11] I. Sakaguchi, T. Momose, T. Kasubuchi, Decrease in thermal conductivity with increasing temperature in nearly dry sandy soil, Eur. J. Soil Sci. 58 (1) (2007) 92-97.

[12] K. Menberg, P. Blum, A. Schaffitel, P. Bayer, Long-term evolution of anthropogenic heat fluxes into a subsurface urban heat island, Environ. Sci. Technol. 47 (17) (2013) 9747-9755.

[13] S.B. Fey, A.N. Mertens, L.J. Beversdorf, K.D. McMahon, K.L. Cottingham, Recognizing cross-ecosystem responses to changing temperatures: soil warming impacts pelagic food webs, Oikos 124 (2015) 1473-1481.

[14] N.B. Grimm, S.H. Faeth, N.E. Golubiewski, C.L. Redman, J. Wu, X. Bai, J.M. Briggs, Global change and the ecology of cities, science 3198 (5864) (2008) 756-760.

[15] R.V. Pouyat, D.E. Pataki, K.T. Belt, P.M. Groffman, J. Hom, L.E. Band, Effects of Urban Land-use Change on Biogeochemical Cycles, Terrestrial Ecosystems in a Changing World, Springer, 2007, pp. 45-58.

[16] M. Schütt, W. Borken, O. Spott, C.F. Stange, E. Matzner, Temperature sensitivity of $\mathrm{C}$ and $\mathrm{N}$ mineralization in temperate forest soils at low temperatures, Soil Biol. Biochem. 69 (2014) 320-327.

[17] R.H. Whittaker, Gradient analysis of vegetation*, Biol. Rev. 42 (2) (1967) 207-264.

[18] M. Luck, J. Wu, A gradient analysis of urban landscape pattern: a case study from the Phoenix metropolitan region, Arizona, USA, Landsc. Ecol. 17 (4) (2002) 327-339.

[19] Q. Wu, D. Hu, R. Wang, H. Li, Y. He, M. Wang, B. Wang, A GIS-based moving window analysis of landscape pattern in the Beijing metropolitan area, China, Int. J. Sustain. Dev. World Ecol. 13 (5) (2006) 419-434.

[20] Y. Bai, J. Wu, C.M. Clark, Q. Pan, L. Zhang, S. Chen, Q. Wang, X. Han, Grazing alters ecosystem functioning and C: N: P stoichiometry of grasslands along a regional precipitation gradient, J. Appl. Ecol. 49 (6) (2012) 1204-1215.

[21] W.J. Parton, J.A. Logan, A model for diurnal variation in soil and air temperature, Agric. Meteorol. 23 (1981) 205-216.

[22] S. Kang, S. Kim, S. Oh, D. Lee, Predicting spatial and temporal patterns of soil temperature based on topography, surface cover and air temperature, For. Ecol. Manag. 136 (1-3) (2000) 173-184.

[23] G. Mihalakakou, M. Santamouris, D. Asimakopoulos, A. Argiriou, On the ground temperature below buildings, Sol. energy 55 (5) (1995) 355-362.

[24] K. Landman, A. Delsante, Steady-state heat losses from a building floor slab with horizontal edge insulation, Build. Environ. 22 (1) (1987) 57-60.

[25] B. Givoni, Cooled soil as a cooling source for buildings, Sol. Energy 81 (3) (2007) 316-328.

[26] A. de Gracia, A. Castell, C. Fernández, L.F. Cabeza, A simple model to predict the thermal performance of a ventilated facade with phase change materials, Energy Build. 93 (2015) 137-142.

[27] T.T. Chow, A.L.S. Chan, K.F. Fong, Z. Lin, Hong Kong solar radiation on building facades evaluated by numerical models, Applied Thermal Engineering 25 (13) (2005) 1908-1921.

[28] M.A. Shao, Q.J. Wang, M.B. Huang, Soil Physics, Higher Education Press, Beijing, 2006.

[29] H. Zhou, D. Hu, X. Wang, F. Han, Y. Li, X. Wu, S. Ma, Horizontal heat impact of urban structures on the surface soil layer and its diurnal patterns under different micrometeorological conditions, Sci. Rep. 6 (2016) 18790.

[30] H. Zhou, Y. Li, K. Xu, H. Zhang, D. Hu, X. Wang, F. Han, X. Wang, A continuous 
dynamic feature of the distribution of soil temperature and horizontal heat flux next to external walls in different orientations of construction sites in the autumn of Beijing, China, J. Clean. Prod. http://dx.doi.org/10.1016/j.jclepro. 2015.10.120.

[31] W. Dorigo, W. Wagner, R. Hohensinn, S. Hahn, C. Paulik, A. Xaver, A. Gruber, M. Drusch, S. Mecklenburg, P.v. Oevelen, The international soil moisture network: a data hosting facility for global in situ soil moisture measurements, Hydrol. Earth Syst. Sci. 15 (5) (2011) 1675-1698.

[32] T.R.H. Holmes, T.J. Jackson, R.H. Reichle, J.B. Basara, An assessment of surface soil temperature products from numerical weather prediction models using ground-based measurements, Water Resour. Res. 48 (2) (2012) W02531.

[33] Z. Su, J. Wen, L. Dente, R. Velde, L. Wang, Y. Ma, K. Yang, Z. Hu, The Tibetan Plateau observatory of plateau scale soil moisture and soil temperature (TibetObs) for quantifying uncertainties in coarse resolution satellite and model products, Hydrol. Earth Syst. Sci. 15 (7) (2011) 2303-2316.

[34] M. Wallenstein, S. Allison, J. Ernakovich, J.M. Steinweg, R. Sinsabaugh, Controls on the temperature sensitivity of soil enzymes: a key driver of in situ enzyme activity rates, in: G. Shukla, A. Varma (Eds.), Soil Enzymology, Springer Berlin Heidelberg, 2011, pp. 245-258.

[35] D. Weng, Y. Chen, Climatological calculation of downward atmospheric radiation for China and its characteristic distribution, J. Nanjing Inst. Meteorol. 15 (1) (1992) 1-9.

[36] S. Wang, H. Cheng, The calculation of saturated vapor pressure of water, Henan Chem. Ind. 287 (11) (1999) 29-30.

[37] J. Oksanen, F.G. Blanchet, R. Kindt, P. Legendre, P.R. Minchin, R. O'Hara, G.L. Simpson, P. Solymos, M. Henry, H. Stevens, Vegan: Community Ecology Package, R Package version 2.0-3. 2012, 2013.

[38] R.K. Heikkinen, M. Luoto, R. Virkkala, K. Rainio, Effects of habitat cover, landscape structure and spatial variables on the abundance of birds in an agricultural-forest mosaic, J. Appl. Ecol. 41 (5) (2004) 824-835.

[39] X. Li, W. Zhou, Z. Ouyang, W. Xu, H. Zheng, Spatial pattern of greenspace affects land surface temperature: evidence from the heavily urbanized Beijing metropolitan area, China, Landsc. Ecol. 27 (6) (2012) 887-898.

[40] S. Meier, M. Luoto, J. Soininen, The effects of local, buffer zone and geographical variables on lake plankton metacommunities, Hydrobiologia 743 (1) (2015) 175-188.

[41] X. Han, Y. Jing, G. Li, Relationships between soil moisture variability and meteorological factors on low hill red soil slope: a redundancy analysis, Chin. J. Ecol. 32 (9) (2013) 2368-2374.

[42] I.N. Harman, The Energy Balance of Urban Areas, University of Reading, 2003.

[43] H. Wang, Z. Ouyang, W. Chen, X. Wang, H. Zheng, Y. Ren, Water, heat, and airborne pollutants effects on transpiration of urban trees, Environ. Pollut. 159 (8) (2011) 2127-2137.

[44] C.J. Walsh, P.J. Papas, D. Crowther, P.T. Sim, J. Yoo, Stormwater drainage pipes as a threat to a stream-dwelling amphipod of conservation significance Austrogammarus australis, in southeastern Australia, Biodivers. Conservat. 13 (4) (2004) 781-793.

[45] K. Menberg, P. Bayer, K. Zosseder, S. Rumohr, P. Blum, Subsurface urban heat islands in German cities, Sci. Total Environ. 442 (2013) 123-133.

[46] J. Zheng, How does ventilation control temperature of subway tunnel? Undergrourd Eng. Tunmels 34 (2) (2004) 40-42.

[47] X. Gou, Z. Xia, J. Wu, R. Wang, Y. Meng, Research and optimum analysis on temperature field prediction of underground power transmission tunnel, J. Eng. Thermophys. 31 (5) (2010) 827-830.

[48] M. Wu, G. Jiang, B. An, Numerical calculation for soil temperature field of oil pipeline, J. Petrochem. Univ. 14 (4) (2001) 54-57.

[49] S. Rees, H. Thomas, Two-dimensional heat transfer beneath a modern commercial building: comparison of numerical prediction with field measurement, Build. Serv. Eng. Res. Technol. 18 (3) (1997) 169-174.

[50] H. Thomas, S. Rees, The thermal performance of ground floor slabs-a full scale in-situ experiment, Build. Environ. 34 (2) (1998) 139-164.

[51] S.A. Benz, P. Bayer, K. Menberg, S. Jung, P. Blum, Spatial resolution of anthropogenic heat fluxes into urban aquifers, Sci. Total Environ. 524 (2015) 427-439.

[52] Y. Fan, W. Sheng, L. Du, Z. Feng, Comparison and analysis of temperature on various underlying surfaces in summer, Atmos. Sci. Res. Appl. 31 (2) (2008) $43-51$.

[53] H. Huang, H. Dong, Y. Ling, X. Li, Characteristic analysis and prediction of temperature on different underlying surfaces in summer in Nanning, Meteorological Sci. Technol. 31 (4) (2003) 253-256.

[54] J. Zhang, H. Liang, X. Jiang, C. Yang, G. Chen, The summer temperature characteristics on different underlying surfaces in Shenyang and application to meteorologic services, Sci. Meteorol. Sin. 28 (5) (2008) 528-532.

[55] C. Liu, B. Shi, C. Tang, L. Gao, A numerical and field investigation of underground temperatures under Urban Heat Island, Build. Environ. 46 (5) (2011) 1205-1210.

[56] H. Takebayashi, M. Moriyama, Surface heat budget on green roof and high reflection roof for mitigation of urban heat island, Build. Environ. 42 (8) (2007) 2971-2979.

[57] X. Feng, D. Cai, Soil temperature in relation to air temperature, altitude and latitude, Acta Pedol. Sin. 41 (3) (2004) 489-491. 